\title{
Unisexual Reproduction in Huntiella moniliformis
}

\author{
A.M. Wilson ${ }^{\mathrm{a}}$, T. Godlonton ${ }^{\mathrm{a}}$, M.A. van der Nest $^{\mathrm{a}}$, P.M. Wilken ${ }^{\mathrm{a}}$, M.J. Wingfield ${ }^{\mathrm{b}}$, B.D. \\ Wingfield ${ }^{\mathrm{a},{ }^{*}}$ \\ a Department of Genetics, Forestry and Agricultural Biotechnology Institute, University of Pretoria, Private Bag \\ X20, Hatfield, Pretoria 0028, South Africa \\ ${ }^{\mathrm{b}}$ Department of Microbiology and Plant Pathology, Forestry and Agricultural Biotechnology Institute, University of \\ Pretoria, Private Bag X20, Hatfield, Pretoria 0028, South Africa \\ * Corresponding author
}

\section{Contact Details}

Email Address: brenda.wingfield@fabi.up.ac.za

Telephone number: +27 124206471

\section{ABSTRACT}

Sexual reproduction in fungi is controlled by genes present at the mating type (MAT) locus, which typically harbours transcription factors that influence the expression of many sex-related genes. The MAT locus exists as two alternative idiomorphs in ascomycetous fungi and sexual reproduction is initiated when genes from both idiomorphs are expressed. Thus, the gene content of this locus determines whether a fungus is heterothallic (self-sterile) or homothallic (self-fertile). Recently, a unique sub-class of homothallism has been described in fungi, where individuals possessing a single MAT idiomorph can reproduce sexually in the absence of a partner. Using various mycological, molecular and bioinformatic techniques, we investigated the sexual strategies and characterized the MAT loci in two tree wound-infecting fungi, Huntiella moniliformis and Huntiella omanensis. H. omanensis was shown to exhibit a typically heterothallic sexual reproductive cycle, with isolates possessing either the MAT1-1 or MAT1-2 idiomorph. This was in contrast to the homothallism via unisexual reproduction that was shown in $H$. moniliformis, where only the MAT1-2-1 gene was present in sexually reproducing cultures. While the evolutionary benefit and mechanisms underpinning a unisexual mating strategy remain unknown, it could 
have evolved to minimize the costs, while retaining the benefits, of normal sexual reproduction.

\section{KEYWORDS}

- Ceratocystis

- Huntiella

- Unisexual reproduction

- $\quad$ Mating type (MAT) locus

- Heterothallic

\section{INTRODUCTION}

Despite being a costly process, sexual reproduction allows for the generation of genetic diversity and can act to purge deleterious alleles from a population (BARTON 2009; NIELSEN 2006). These benefits likely explain the ubiquitous nature of sex in the Eukaryota (NIELSEN 2006). While many fungi are able to reproduce asexually, sexual reproduction is found in all four major fungal phyla (LEE et al. 2010). The numerous and diverse strategies employed by these organisms to retain sexual reproduction, demonstrates the benefits of preserving this type of reproduction, whilst also providing numerous opportunities to minimize the high costs associated with this process (ROACH et al. 2014).

Sexual reproduction in fungi is controlled by genes present at the mating type (MAT) locus, which are typically involved in the transcriptional regulation of other sexrelated genes, such as those involved in mate recognition and meiosis (KRONSTAD and StABEN 1997). In the ascomycetes, this locus has two alternative forms, known as the MAT1-1 and MAT1-2 idiomorphs, which possess non-allelic gene combinations (METZENBERG and Glass 1990). The MAT1-1 idiomorph characteristically possesses, at minimum, the MAT1-1-1 gene, which encodes a protein with an alpha box DNA-binding domain, and is homologous to MATa1 of Saccharomyces cerevisiae (TURGEON and YODER 2000). Other genes, including MAT1-1-2 and MAT1-1-3 can also be present in the idiomorph (FERREIRA et al. 1996; 
WILKEN et al. 2014). Similarly, the MAT1-2 idiomorph typically harbours the MAT1-21 gene, encoding an HMG box protein (TURGEON and YODER 2000). Although this is generally the only gene present at this locus, other genes including the MAT1-2-2, MAT1-2-3, MAT1-2-4 and MAT1-2-5 genes have also been described and are named in the order of their discovery (BIHON et al. 2014; MANDEL et al. 2007; MARTIN et al. 2011; PÖGGELER and KÜCK 2000). The expression of genes from both these idiomorphs is typically required for the completion of a sexual cycle (COPPIN et al. 1997) and thus, fungal mating systems can be classified based on the structure and gene content of the MAT locus.

Sexual reproduction has classically been divided into two mating systems. Of these, heterothallism is characterized by the requirement of two compatible mating partners for sexual reproduction (KRONSTAD and STABEN 1997). In this case, each self-sterile partner possesses genes from a different MAT idiomorph and the combined expression of both idiomorphs results in a successful mating interaction. Species exhibiting heterothallism are wide-spread (BILLIARD et al. 2012) and include commonly studied fungi such as Neurospora crassa and Podospora anserina (GLASS et al. 1990a; PICARD et al. 1991). In contrast, homothallism represents a situation where a single individual is able to progress through a full sexual cycle without an opposite mating partner (KRONSTAD and STABEN 1997). Homothallic fungi are thus self-fertile and typically possess genes from both MAT idiomorphs in a single genome (CoppIN et al. 1997).

Homothallism encompasses a heterogeneous assemblage of mechanisms and it has thus been further sub-divided into discrete categories. These include primary homothallism (LIN and HEITMAN 2007), as exhibited by Sodaria macrospora where both MAT idiomorph genes are present in a single genome (PöGGELER et al. 1997); mating type switching, found in $S$. cerevisiae where the MAT locus identity can change via gene conversion (HABER 1998) and pseudohomothallism, such as that occurring in $N$. tetrasperma where nuclei of opposite mating types are packaged in a single ascospore (MERINO et al. 1996). A unique sub-class of homothallism known as unisexual reproduction has also been discovered in fungi, including four Neurospora spp., Cryptococcus neoformans and Candida albicans (Alby and BenNetT 2011; GLASS and SMITH 1994; LIN et al. 2005). In unisexual reproduction, also known as same-sex mating, isolates with only a single mating type have the ability to initiate 
and proceed through an entire sexual cycle. This can occur within a single cell or between two cells of different lineage, but identical mating type (ROACH et al. 2014).

Fungal species in the Ceratocystidaceae (DE BEER et al. 2014) include tree-infecting species and important tree pathogens in genera such as Ceratocystis (WINGFIELD et al. 2012). Genera in this family typically exhibit a wide variety of sexual reproductive strategies, including heterothallism as employed by Davidsoniella eucalypti (KILE et al. 1996), primary homothallism as seen in Thielaviopsis cerberus (MBENOUN et al. 2014) and homothallism via unidirectional mating type switching as observed in $\mathrm{Ce}$. fimbriata (HARRINGTON and MCNEW 1997; WILKEN et al. 2014; WITTHUHN et al. 2000).

Species in the genus Huntiella, previously accommodated in the Ce. moniliformis complex (DE BEER et al. 2014), have been described as homothallic (AL-SUBHI et al. 2006; HARRINGTON 2007). However, these species are cosmopolitan saprobes occurring on freshly made tree wounds (VAN WYK et al. 2006) and their mating strategies have not been intensively studied. The aim of this study was to investigate the mating strategy and characterize the MAT loci of two Huntiella species, $H$. omanensis and $H$. moniliformis.

\section{METHODS AND MATERIALS}

\subsection{Sexual Reproduction in Huntiella omanensis and $\boldsymbol{H}$. moniliformis Cultures}

Two isolates of $H$. omanensis and eight isolates $H$. moniliformis were used in this study (Table 1). All cultures are preserved in the culture collection (CMW) of the Forestry and Agricultural Biotechnology Institute (FABI), University of Pretoria. The isolates were grown and maintained on $2 \%$ malt extract agar plates $\left(20 \mathrm{~g} . \mathrm{L}^{-1}\right.$ malt extract (Biolab, Merck), 20 g. $\mathrm{L}^{-1}$ agar (Biolab, Merck), supplemented with thiamine (100mg/l, SIGMA, Steinheim, Germany) and streptomycin (150mg/l, SIGMA, Steinheim, Germany), forthwith referred to as MEA-ST plates. The cultures were kept at $22^{\circ} \mathrm{C}$ for the duration of the study.

$H$. omanensis and $H$. moniliformis isolates that produced mature sexual structures (ascomata from which ascospore masses exuded) were used as parental cultures from which single ascospore progeny were generated. These isolates were 


\section{Table 1: Huntiella moniliformis and H. omanensis Isolates Used in This Study}

\begin{tabular}{|c|c|c|c|}
\hline Species & CMW Number ${ }^{a}$ & Details of Isolation (Host, Country, Locality, Year) & Sporulating \\
\hline H. moniliformis & 10134 & Eucalyptus grandis, South Africa, Mpumalanga, 2002 & Yes \\
\hline H. moniliformis & 36895 & Theobroma cacao, Cameroon, Ebolowa, 2009 & Yes \\
\hline H. moniliformis & 36896 & Theobroma cacao, Cameroon, Ebolowa, 2009 & Yes \\
\hline H. moniliformis & 36897 & Theobroma cacao, Cameroon, Ebolowa, 2009 & Yes \\
\hline H. moniliformis & 36908 & Theobroma cacao, Cameroon, Bokito, 2009 & Yes \\
\hline H. moniliformis & 36919 & Theobroma cacao, Cameroon, Ngomedzap, 2009 & Yes \\
\hline H. moniliformis & 36923 & Theobroma cacao, Cameroon, Ngomedzap, 2009 & No \\
\hline H. moniliformis & 37105 & Terminalia superbra, Cameroon, Ngomedzap, 2009 & No \\
\hline H. omanensis & 11046 & Mangifera indica, Oman, 2003 & Yes \\
\hline H. omanensis & 11046.1 & Single spore progeny of CMW $11046\left(\right.$ MAT1-2) ${ }^{b}$ & No \\
\hline H. omanensis & 11046.2 & Single spore progeny of CMW $11046($ MAT1-1) & No \\
\hline H. omanensis & 11046.3 & Single spore progeny of CMW $11046\left(\right.$ MAT1-2) ${ }^{b}$ & No \\
\hline H. omanensis & 11046.4 & Single spore progeny of CMW $11046\left(\right.$ MAT1-2) ${ }^{b}$ & No \\
\hline H. omanensis & 11046.5 & Single spore progeny of CMW $11046($ MAT1-1) & No \\
\hline H. omanensis & 11056 & Mangifera indica, Oman, 2003 & Yes \\
\hline H. omanensis & 11056.1 & Single spore progeny of CMW $11056($ MAT1-1) & No \\
\hline H. omanensis & 11056.2 & Single spore progeny of CMW $11056\left(\right.$ MAT1-2) ${ }^{b}$ & No \\
\hline H. omanensis & 11056.3 & Single spore progeny of CMW $11056($ MAT1-1) & No \\
\hline H. omanensis & 11056.4 & Single spore progeny of CMW $11056($ MAT1-1) & No \\
\hline H. omanensis & 11056.5 & Single spore progeny of CMW $11056\left(\right.$ MAT1-2) ${ }^{b}$ & No \\
\hline
\end{tabular}

generated by soaking ascospore masses in $20 \mu$ l Soltrol 130 oil (Chemfit, Gauteng, SA) and streaking them out on fresh MEA plates. After approximately 12 hours, individual germinating ascospores were transferred to fresh MEA-ST plates and allowed to grow for 10 to 15 days. These single ascospore progeny were then visually screened for the presence of ascomata exuding ascospore masses. The 
production of ascomata and ascospore masses was used as an indication of successful sexual reproduction.

Cultures that had not shown signs of ascomatal production were then paired in all possible combinations with other non-sporulating cultures. This involved placing a mycelium-covered agar block from each partner approximately $2 \mathrm{~cm}$ apart on a single 2\% MEA-ST plate. The paired cultures were allowed to grow for 10 days, and were then screened daily for the presence of ascomata. In order to test the viability of the ascospore masses produced by these cultures, two to three masses per culture were transferred to fresh $2 \%$ MEA plates and allowed 10 to 15 days to grow.

In addition to the intra-species crosses performed between non-sporulating isolates, inter-species crosses between $H$. omanensis and $H$. moniliformis isolates were also conducted. The culturing method used was the same as that for the intra-species pairings. In this case, MAT1 single ascospore isolates produced from $\mathrm{H}$. omanensis (CMW 11056) were co-incubated with all eight isolates of $H$. moniliformis. Furthermore, MAT2 single ascospore isolates produced from $H$. omanensis (CMW 11056) were also co-incubated with the $H$. moniliformis isolates.

Micrographs of the ascomata and ascospores were captured using an AxioCAm MRc mounted on a Zeiss Axioskop 2 Plus compound microscope. The ascomata at different stages of development were prepared and arranged for microscopy on $2 \%$ MEA medium, whereas the hyphae and ascomatal bases were prepared on glass slides and mounted in $85 \%$ lactic acid.

\subsection{MAT Gene Discovery and MAT Locus Structure}

The genes present at and associated with the MAT locus in Ce. fimbriata (accession number KF033902, WILKEN et al. 2014) were used in local tBLASTn searches against the draft genome assembly of $H$. omanensis (accession number JMSH00000000, VAN DER NEST et al. 2014b) as well as the draft genome assembly of $H$. moniliformis (accession number JSUI00000000, VAN DER NEST et al. 2014a) using CLC Genomics Workbench 7.5 (CLC Bio, Denmark). These included the MAT genes: MAT1-1-1, MAT1-1-2 and MAT1-2-1 as well as the MAT locus-associated genes: Cytoskeleton assembly protein (SLA), Anaphase promoting complex (APC) 
and DNA lyase $(A P N)$. Furthermore, a number of other MAT1-1 gene sequences from various ascomycetous fungi were used in local tBLASTn searches against the two genome assemblies (Table 3).

Contigs showing hits with an E-value of $10^{-5}$ or less for the MAT and MAT locusassociated genes were subjected to gene prediction using the web-based AUGUSTUS gene prediction tool (STANKE et al. 2004). These contigs were annotated using the AUGUSTUS GFF output file and the "annotate with GFF/GTF/GVF file" function on CLC Main Workbench 6.8 (CLC Bio, Denmark). Gene identity was confirmed using these sequences as queries in an NCBI BLASTn search within the non-redundant nucleotide database (ALTSCHUL et al. 1990). Any MAT genes identified in $H$. omanensis were used as queries in local tBLASTn searches against the $H$. moniliformis genome.

The corresponding nucleotide sequences of the MAT and MAT locus-associated genes in $H$. omanensis were compared with those in $H$. moniliformis. This involved aligning the homologs with a gap cost of 10.0 and a gap extension cost of 1.0 , before calculating percentage identity using the "create pairwise comparison" option in CLC Main Workbench 6.8. The coding sequence (CDS) of each gene was also translated to its corresponding amino acid sequence, aligned and compared using the technique described above. The translated amino acid sequence of the MAT and MAT locus-associated genes were also subjected to conserved domain prediction. This was completed using NCBI Conserved Domain Search (MARCHLER-BAUER et al. 2011), InterPro Protein Sequence Analysis and Prediction (HUNTER et al. 2011) as well as PROSITE (SIGRIST et al. 2012), using the default settings for each tool.

In addition, the raw sequence data generated during the sequencing of both genomes was mapped to the MAT regions of the sister species. To do this, the raw data for each species was obtained from the authors (VAN DER NEST et al. 2014a; VAN DER NEST et al. 2014b). The $H$. moniliformis MAT locus was used as a reference sequence to which the raw reads from the $H$. omanensis genome were mapped. Similarly, the raw reads from the $H$. moniliformis genome were mapped to the $H$. omanensis MAT loci. Both of the analyses were carried out in CLC Genomics Workbench 7.5. 


\subsection{Screening for MAT Genes in Huntiella Isolates}

A PCR approach was used to determine which of the MAT genes were present in $H$. omanensis and $H$. moniliformis cultures for which genome sequence was not available. This included cultures preserved in the CMW culture collection as well as at least six single spore isolates generated from each sporulating culture. To do this, PCR primers were designed using CLC Main Workbench 6.8 (Table 2). Primers for MAT1-1-1 (targeting the conserved alpha box) and MAT1-1-2 were designed based on the $H$. omanensis gene sequences. Primers for MAT1-2-1 were designed based on an alignment of the $H$. omanensis and $H$. moniliformis gene sequences, using areas conserved between the two species as target sites.

\begin{tabular}{cccc}
\hline \multicolumn{2}{l}{ Table 2: MAT Gene Primer Sequences } & \\
\hline Primer Name & Sequence $\left(\mathbf{5}^{\prime} \rightarrow \mathbf{3}^{\prime}\right)$ & Target Gene & Amplicon Size (bp) \\
Oman_111_F & CGGCTCATCCCCAAATCT & MAT1-1-1 & 335 \\
Oman_111_R & AGCTCCCCTACTTCGTTAC & & 298 \\
Oman_112_F & GGGATTGAGACCGGCAAA & MAT1-1-2 & \\
Oman_112_R & CAGTTCGTGTTTTCTCTGT & & 572 \\
Om_Mo_121_F & ATTGCTGGCTGATTTCACG & MAT1-2-1 & \\
Om_Mo_121_R & TAGTCTGGGTGGGTGTTC & &
\end{tabular}

DNA was extracted for PCR from 6 to 8-day-old cultures that were grown on $2 \%$ MEA-TS plates. Mycelium was harvested by scraping the surface of cultures before using a standard phenol/chloroform extraction method (PŁAZA et al. 2004). Standard $25 \mu$ I PCR reactions were subsequently conducted using the protocol supplied with KAPA Taq (KapaBiosystems, Massachusetts, USA). The protocol required 1X Buffer $\mathrm{A}, \mathrm{MgCl}_{2}$ at $1.5 \mathrm{mM}$, total dNTPs at $0.8 \mathrm{mM}$, forward and reverse primers at $0.5 \mu \mathrm{M}$ each, 1 unit of KAPA Taq and approximately $25 \mathrm{ng}$ of DNA. Amplification was carried out on a BioRad C1000 Touch $^{\text {TM }}$ thermocycler (BioRad, California, USA) using the following protocol: initial denaturation at $95^{\circ} \mathrm{C}$ for $3 \mathrm{~min}, 35$ cycles of denaturation $\left(95^{\circ} \mathrm{C}\right.$ for $\left.30 \mathrm{sec}\right)$, annealing $\left(53^{\circ} \mathrm{C}\right.$ for $\left.30 \mathrm{sec}\right)$ and extension $\left(72^{\circ} \mathrm{C}\right.$ for $\left.1 \mathrm{~min}\right)$ and a final extension at $72^{\circ} \mathrm{C}$ for $1 \mathrm{~min}$. The products were kept at $4^{\circ} \mathrm{C}$ until they were electrophoresed through $2 \%(\mathrm{w} / \mathrm{v})$ agarose gels at $80 \mathrm{~V}$ for $45 \mathrm{~min}$. 
PCR products were purified using the Zymo Research DNA Clean and ConcentratorTM-5 Kit (Zymo Research Corporation, Irvine, USA) following the manufacturer's protocol for dsDNA products. The purified products were then cyclesequenced using a sequencing reaction with the BigDye $\AA$ Terminator Cycle Sequencing Kit v3.1 (Life Technologies, Carlsbad, USA), also per the manufacturer's instructions. The sequencing protocol was carried out on a Bio-Rad C1000 TouchTM Thermal Cycler. Finally, the sequencing products were precipitated using a standard ethanol precipitation protocol (SAMBROOK et al. 1989) and submitted to the Bioinformatics and Computational Biology Unit at the University of Pretoria for Sanger sequencing.

\section{RESULTS}

\subsection{Sexual Reproduction in Huntiella omanensis and $\boldsymbol{H}$. moniliformis Cultures}

Visual inspection revealed that the $H$. omanensis cultures used in this study were able to produce ascomata and viable ascospores after 10 to 15 days of growth (Figure $1 \mathrm{~A}$ ). The single ascospore isolates generated from these parental cultures were unable to reproduce sexually in isolation. However, when these isolates were paired in various combinations, ascomata and ascospores were once again produced in a number of the crosses (Figure 2, A \& D).

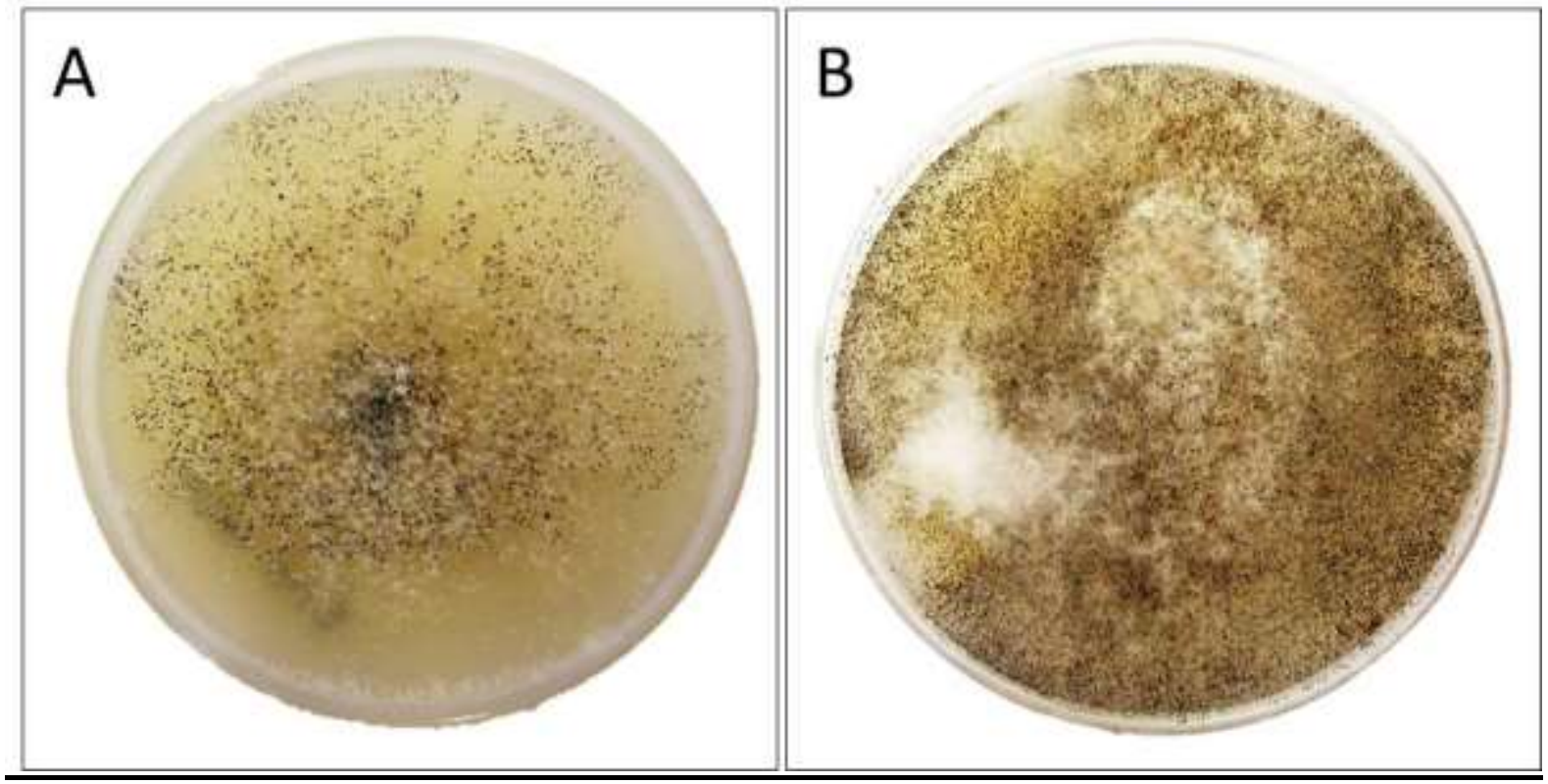

Figure 1: Sporulating cultures of the two Huntiella species. A: H. omanensis undergoes sexual reproduction when two opposite mating types isolates are cultured together. $\mathbf{B}$ : H. moniliformis is able to undergo sexual reproduction from single isolated ascospores. 
Of the eight $H$. moniliformis cultures used in this study, six were able to produce ascomata and viable ascospores after 10 to 15 days of growth (Figure 1B). An average of five of the six single ascospore progeny generated from each of the parental $H$. moniliformis cultures retained their ability to reproduce sexually (Figure 2, e \& h). When paired in various combinations, however, none of the sterile $H$. moniliformis isolates produced ascomata.

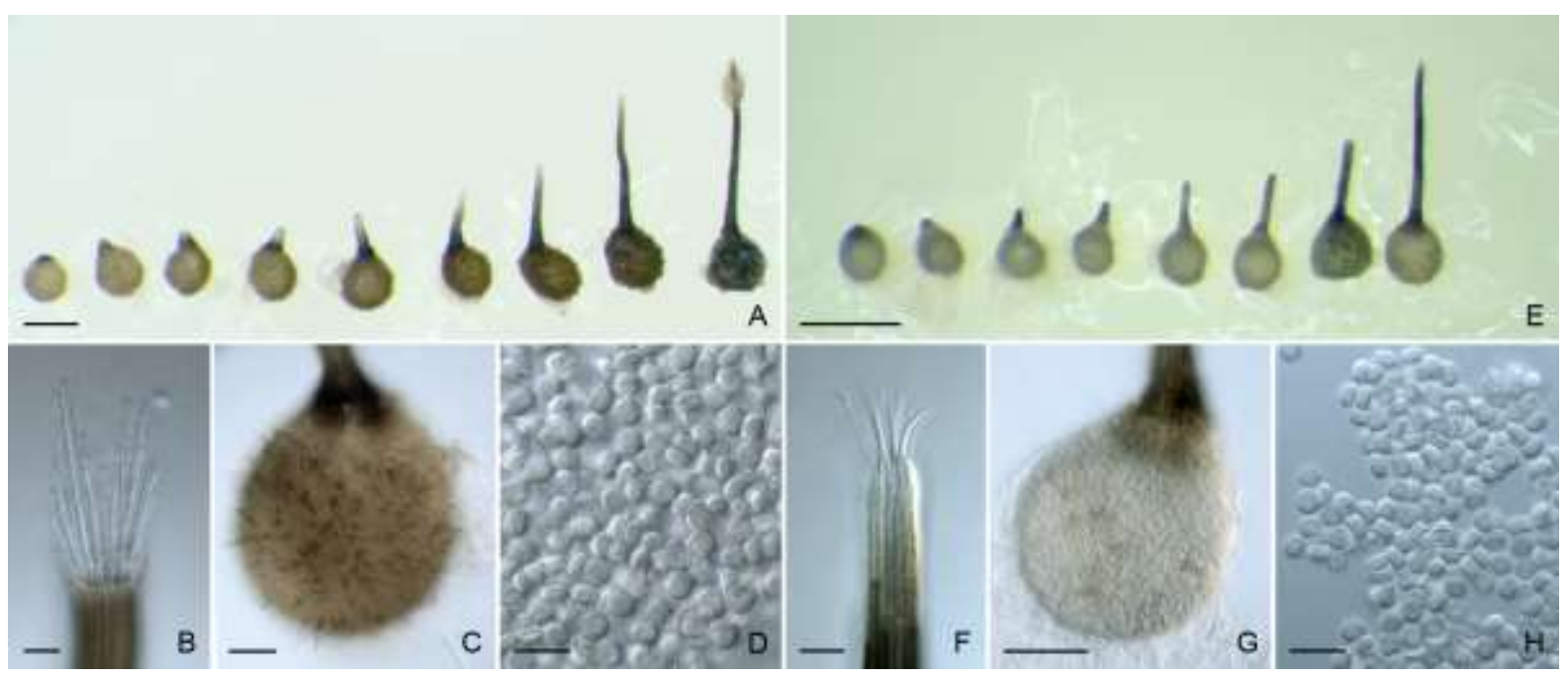

Figure 2: Microscope images of characteristics representing the sexual structures of $\mathrm{H}$. omanensis (A-D) and $H$. moniliformis (E-H). A \& E: Ascomata at different stages of development, from young (left) to mature (right). B \& F: Divergent ostiolar hyphae. C \& G: Ascomatal bases. D \& H: Hat-shaped ascospores. Scale bars: $\mathbf{A} \& \mathbf{E}=200 \mu \mathrm{m} ; \mathbf{B}, \mathbf{F}, \mathbf{D} \& \mathbf{H}=10 \mu \mathrm{m} ; \mathbf{C} \& \mathbf{G}=50 \mu \mathrm{m}$.

No successful mating was observed in the inter-species crosses performed between isolates of $H$. omanensis and $H$. moniliformis. The various MAT1 and MAT2 $H$. omanensis isolates were unable to reproduce sexually and form ascomata and ascospores when cultured alongside any of the eight $H$. moniliformis isolates. Thus, there was no evidence of hybridization between the two species.

\subsection{MAT Gene Discovery and MAT Locus Structure}

The tBLASTn searches revealed the presence of MAT1-1-1, MAT1-1-2, MAT1-2-1, $S L A, A P C$ and APN gene homologs in the H. omanensis assembly. The MAT1-1-1 and MAT1-1-2 genes were found together on a single contig, while the MAT1-2-1 gene was found on a separate contig. The MAT1-1 idiomorph (possessing the MAT1-1-1 and MAT1-1-2 genes) as well as the MAT1-2 idiomorph (possessing the MAT1-2-1 gene) were both found to be associated with the SLA and APC genes (Figure $3 \mathrm{~A}$ ). AUGUSTUS predicted an additional two genes flanking the other side of 


\begin{tabular}{|c|c|c|c|}
\hline \multicolumn{4}{|c|}{ Genome Assembly } \\
\hline Gene & Species & NCBI Gene ID/ Accession No. & Reference \\
\hline MAT1-1-1 & Aspergillus flavus & 7920875 & (Yu et al. 2005) \\
\hline MAT1-1-1 & Aspergillus niger & 4985235 & (PEL et al. 2007) \\
\hline MAT1-1-1 & Aspergillus nidulans & BK001307 & (DYER et al. 2003) \\
\hline MAT1-1-1 & Aspergillus oryzae & 5996547 & (MACHIDA et al. 2005) \\
\hline \multirow[t]{2}{*}{ MAT1-1-1 } & Beauveria bassiana & 19890745 & (XIAO et al. 2012) \\
\hline & Fusarium & & \\
\hline \multirow[t]{2}{*}{ MAT1-1-1 } & pseudograminearum & 20366840 & (GARDINER et al. 2012) \\
\hline & Fusarium & & \\
\hline \multirow[t]{2}{*}{ MAT1-1-2 } & pseudograminearum & 20366841 & (GARDINER et al. 2012) \\
\hline & Fusarium & & \\
\hline MAT1-1-3 & pseudograminearum & 20366842 & (GARDINER et al. 2012) \\
\hline MAT1-1-1 & Magnaporthe oryzae & AB080668 & (KANAMORI et al. 2007) \\
\hline \multirow[t]{2}{*}{ MAT1-1-2 } & Magnaporthe oryzae & AB080668 & (KANAMORI et al. 2007) \\
\hline & Mycosphaerella & & \\
\hline MAT1-1-1 & graminicola & 13401352 & (GoodWIN et al. 2011) \\
\hline MAT1-1-1 & Neofusicoccum parvum & 19020696 & (BLANCO-ULATE et al. 2013) \\
\hline MAT A1 & Neurospora crassa & 3880391 & (GALAGAN et al. 2003) \\
\hline MATA2 & Neurospora crassa & 3880488 & (GALAGAN et al. 2003) \\
\hline MAT A3 & Neurospora crassa & 3880489 & (GALAGAN et al. 2003) \\
\hline \multirow[t]{2}{*}{$M A T-$} & Podospora anserina & X64194 & (DEBUChy and CopPIN 1992) \\
\hline & Saccharomyces & & \\
\hline MAT $\alpha$ & cerevisiae & 850407 & (OLIVER et al. 1992) \\
\hline MAT1-1-1 & Trichoderma reesei & FJ599756 & (SEIDL et al. 2009) \\
\hline MAT1-1-2 & Trichoderma reesei & FJ599756 & (SEIDL et al. 2009) \\
\hline MAT1-1-3 & Trichoderma reesei & FJ599756 & (SEIDL et al. 2009) \\
\hline
\end{tabular}

the MAT locus. Neither of these genes showed similarity to any proteins present in the NCBI database. 
In contrast to $H$. omanensis, the tBLASTn searches revealed the presence of the MAT1-2-1, SLA, APC and APN genes in the H. moniliformis genome, while neither the MAT1-1-1 nor the MAT1-1-2 gene was identified. Despite using MAT1-1 gene sequences from many other ascomycetous species (Table 3 ) as search queries, no MAT1-1 gene homologs were ever identified in the H. moniliformis genome. The SLA and $A P C$ genes as well as two unknown genes flanking the MAT locus in $H$. omanensis were present linked to the locus in $H$. moniliformis (Figure 2B). In both species, the APN homolog was found elsewhere in the genome and is not associated with any known MAT genes. This is in contrast to the MAT locus of $\mathrm{Ce}$. fimbriata, where $A P N$ is found downstream of the MAT1-1-1 gene, adjacent to APC (WILKEN et al. 2014).

The structure of the MAT1-2 idiomorph was highly conserved between $H$. moniliformis and $H$. omanensis. In both cases, the SLA and APC genes were found upstream of the MAT1-2-1 gene while two unknown proteins were found downstream. The only notable difference between the two MAT1-2 idiomorphs of these species was the presence of an unknown gene directly upstream of the MAT12-1 gene in $H$. omanensis. Due to this gene's association with the MAT1-2 idiomorph, its absence in the flanking region of the MAT1-1 idiomorph and its lack of homology to any other gene previously observed at the MAT locus, we have designated it as MAT1-2-7. This reflects the fact that it is the seventh gene to have been identified as part of the MAT1-2 locus in ascomycetous fungi. When this gene was used in a local BLASTn search against the $H$. moniliformis genome, the corresponding sequence in $H$. moniliformis showed a $90 \%$ similarity between the two species. However, the region does not encode the full MAT1-2-7 gene present in $H$. omanensis and instead, what is apparently a pseudogene was present. This pseudogene would encode a truncated protein in $H$. moniliformis if it were transcribed and subsequently translated because it possesses a nonsense mutation in the reading frame that produces a premature stop codon. There is no evidence to suggest that there is an intron present which would potentially allow for this region to encode the full gene as observed in $H$. omanensis. This explains why it was not predicted using the default parameters of AUGUSTUS. 


\section{A H. omanensis MAT1-1 Idiomorph}

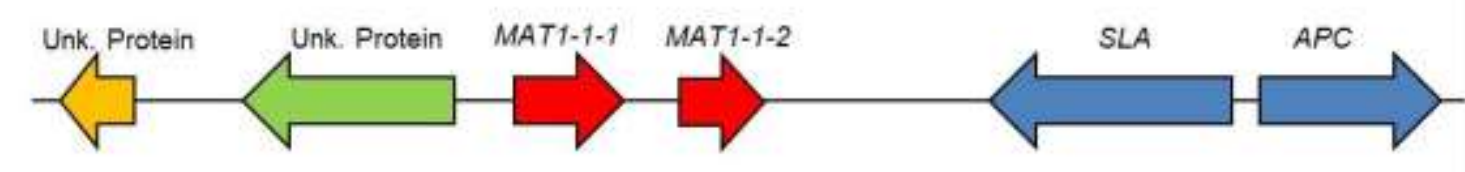

\section{H. omanensis MAT1-2 Idiomorph}

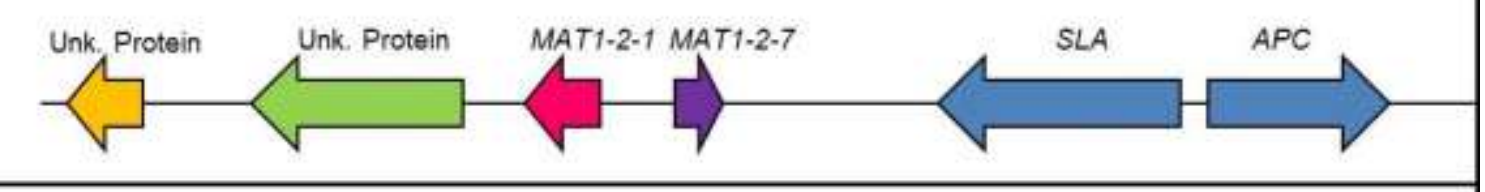

B H. moniliformis MAT1-2 Idiomorph

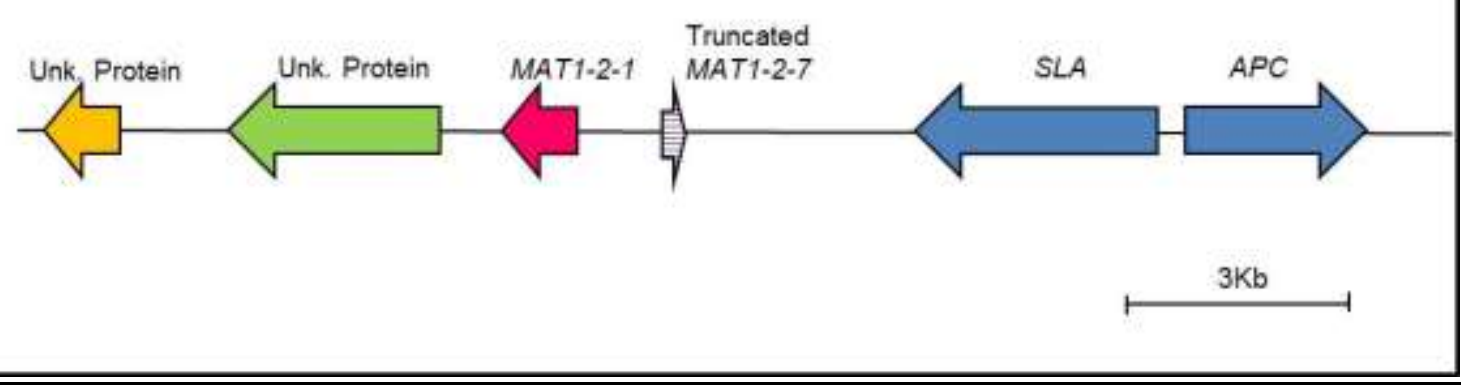

Figure 3: A schematic representation of the $H$. moniliformis and $H$. omanensis MAT loci. A: The MAT1-1 and MAT1-2 idiomorphs of $H$. omanensis. B: The MAT1-2 idiomorph of $H$. moniliformis. Unk. Protein: Unknown Protein.

Significant sequence and structure similarity was seen between the MAT locus and flanking regions of the two Huntiella species. The MAT1-1 idiomorph in $\mathrm{H}$. omanensis possesses the MAT1-1-1 and MAT1-1-2 genes. The predicted MAT1-1-1 gene was 1188bp long, comprised of an 1134bp CDS and a single intron (54bp) and encoded a 377aa protein. The predicted protein harboured the characteristic alpha box that spans the intron. The predicted MAT1-1-2 gene was 1527bp long and was composed of a 1299bp CDS and four introns (65, 48, 54 and 61bp). The gene encoded a 432aa protein, possessing no conserved motifs. The MAT1-2 idiomorph of $H$. omanensis possessed the MAT1-2-1 and MAT1-2-7 genes (Figure 3A). The predicted $H$. omanensis MAT1-2-1 gene was 938bp long and consisted of an $825 \mathrm{bp}$ CDS and two introns $(53,60 \mathrm{bp})$, encoding a $274 \mathrm{aa}$ protein harbouring the characteristic HMG box domain. The predicted MAT1-2-7 gene was 467bp long, did not possess any introns and encodes a putative protein of $155 \mathrm{aa}$ with no conserved 
domains. As in $H$. omanensis, the $H$. moniliformis MAT1-2-1 gene was also 938bp long with an $85 \%$ nucleic acid identity to that of $\mathrm{H}$. omanensis. It was comprised of an $825 \mathrm{bp}$ CDS region and two introns (53,60bp), encoding a 274 aa protein with a $91 \%$ identity to the corresponding protein of $\mathrm{H}$. omanensis. The predicted protein also possessed the characteristic HMG box motif, which has a $97 \%$ identity to the same motif in $H$. omanensis (Figure 4). The truncated MAT1-2-7 gene in $H$. moniliformis was $147 \mathrm{bp}$ long, encoding a protein of only $48 \mathrm{aa}$ and is likely nonfunctional.

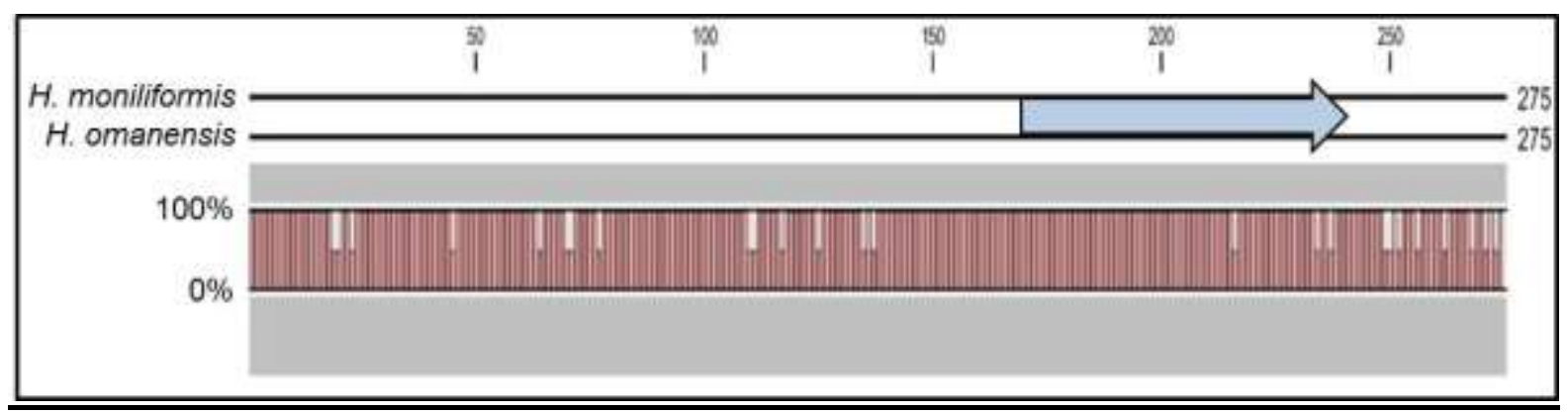

Figure 4: Amino acid alignment of the $H$. moniliformis and $H$. omanensis MAT1-2-1 protein. The proteins show a $91 \%$ similarity across the species. The arrow indicates the position of the conserved HMG box domain, which shows a $97 \%$ similarity.

When the $H$. omanensis MAT1-1 idiomorph was used as a reference, the raw reads from $H$. moniliformis aligned to most of the sequence flanking the MAT locus. No reads aligned to either the MAT1-1-1 or MAT1-1-2 genes, despite an average coverage of $25 \mathrm{X}$ across other genes in the vicinity (Figure $5 \mathrm{~A}$ ). In contrast, the raw genome sequence reads of $H$. moniliformis aligned to all genes (including MAT1-2-1 and MAT1-2-7) and most non-genic sequence present at the MAT1-2 idiomorph of $H$. omanensis (Figure 5B). Although few raw reads from the $H$. moniliformis genome aligned to the unknown protein flanking the $H$. omanensis MAT loci, the gene sequence of this unknown protein shares a $67 \%$ similarity between the two species and can be identified via reciprocal local BLASTn searches. 


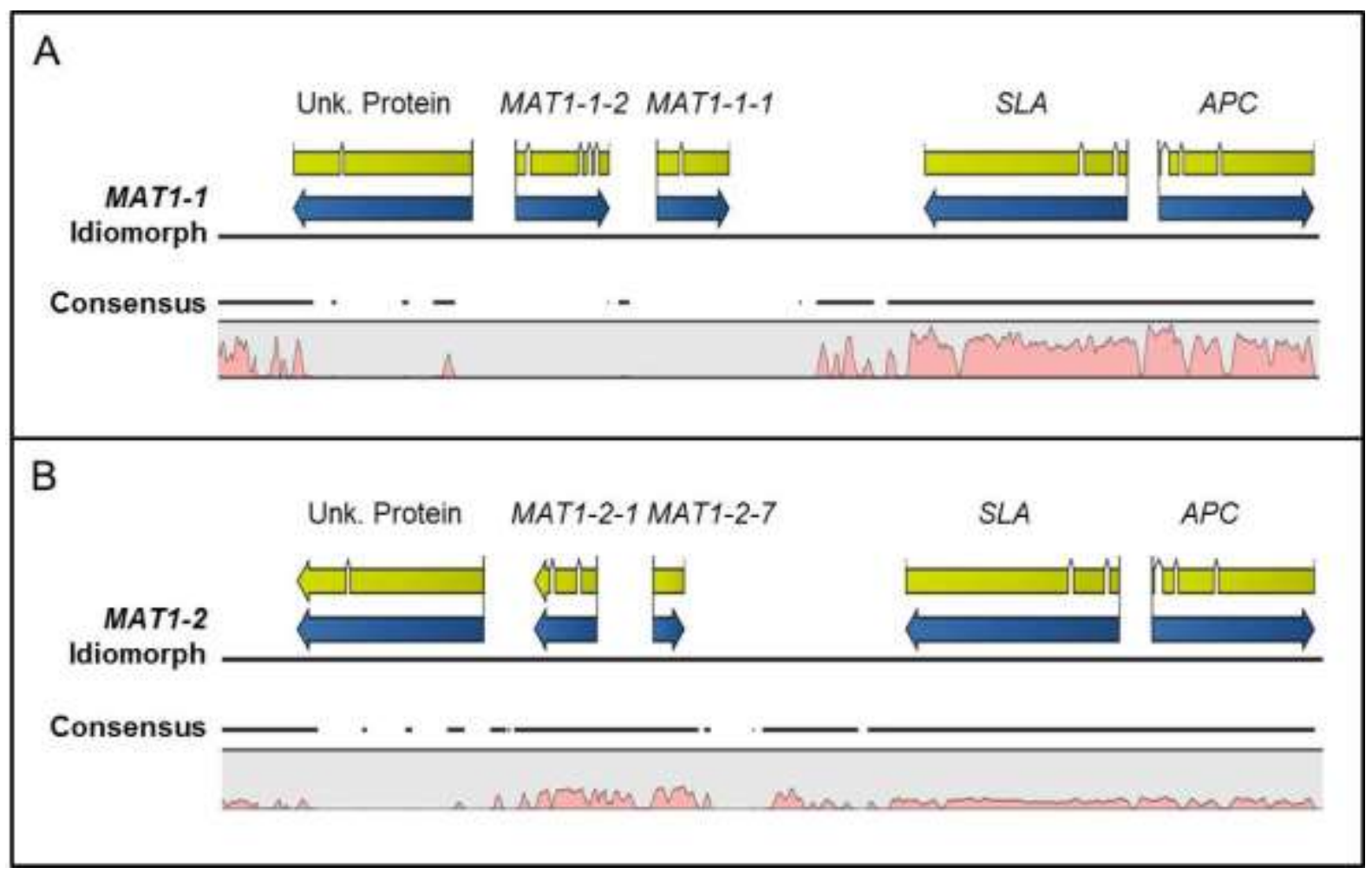

Figure 5: Raw genomic sequence reads of $H$. moniliformis mapped to the two MAT idiomorphs from $H$. omanensis. The consensus sequence indicated by the dotted black line underneath the idiomorphs represents an average coverage of these reads to the reference. This coverage was between 26 and 46X. A) MAT1-1 idiomorph as reference: raw reads map to all MAT locus-flanking genes, but do not map to MAT1-1-1 nor MAT1-1-2. B) MAT1-2 idiomorph as reference: raw reads map to the MAT1-2-1 gene as well as its flanking regions. Unk. Protein: Unknown protein

\subsection{Screening for MAT Genes in Huntiella Isolates}

Genes from both the MAT1-1 and MAT1-2 idiomorphs were successfully amplified from the parental $H$. omanensis cultures. This was expected because the genome assembly also contained both idiomorphs and the presence of both idiomorphs resulted in the production of ascomata. However, only genes from a single idiomorph (either MAT1-1 or MAT1-2) were amplified from the $H$. omanensis non-sporulating, single ascospore isolates. In contrast, MAT1-2-1 was the only gene region to be successfully amplified in all eight $H$. moniliformis cultures used in this study. This gene region was also found in all single ascospore progeny generated from each of the six parental cultures. Once sequenced, these MAT1-2-1 amplicons were shown to be identical for all the parental and single spore progeny. Thus, in both sporulating 
and non-sporulating cultures, the only MAT gene present was MAT1-2-1 and no amplicons corresponding to either of the MAT1-1 genes were present.

\section{DISCUSSION}

The availability of sporulating cultures as well as genome sequences for $H$. omanensis and $H$. moniliformis allowed us to investigate the modes of sexual reproduction and to characterize the MAT loci in these species for the first time. It was intriguing that these species, thought to be closely related (DE BEER et al. 2014), had distinct mating strategies. $H$. omanensis was shown to be heterothallic, with individuals in the natural population possessing either the MAT1-1 idiomorph, harbouring the MAT1-1-1 and MAT1-1-2 genes or the MAT1-2 idiomorph, harbouring the MAT1-2-1 and MAT1-2-7 genes. This was in contrast to $H$. moniliformis, which was found to be self-fertile, with all sporulating and non-sporulating isolates possessing only the MAT1-2-1 gene. This provides evidence for a unisexual reproductive cycle in $H$. moniliformis and is the first record of this strategy in a species of the important fungal family Ceratocystidaceae. In addition to the discovery of this novel mating system, results of this study also showed that the $H$. omanensis MAT1-2 idiomorph harbours an undescribed MAT gene, which we have designated as MAT1-2-7. Remnants of this gene were found in $H$. moniliformis; however a premature in-frame stop codon in the sequence produces a truncated predicted protein.

Results of this study suggested that $H$. omanensis has a typical bipolar heterothallic mating system. Heterothallism involves the presence of a single MAT locus, possessing one of two distinct idiomorphs that confer mating type (COPPIN et al. 1997). Thus, sexual reproduction requires an interaction between two individuals of opposite mating type. This is identical to what was observed in $H$. omanensis, where single ascospore isolates failed to produce sexual structures in culture, unless they were paired with individuals of the opposite mating type. This mating system is similar to that of $D$. eucalypti (KILE et al. 1996), another species in the Ceratocystidaceae that was previously accommodated in Ceratocystis (DE BEER et al. 2014). 
Both the MAT1-1 and MAT1-2 idiomorphs of $H$. omanensis were characterized from the single genome assembly that is publicly available (VAN DER NEST et al. 2014b). Given that the culture-based approach used in this study showed that the species is heterothallic, the presence of both idiomorphs within a single genome sequence seems implausible. The isolate (CMW 11056) from which the genome sequence was generated was obtained from the CMW culture collection and was able to produce abundant ascomata as well as viable ascospores. However, through the production of single ascospore isolates, approximately equal ratios of MAT1 to MAT2 individuals were recovered, neither of which were able to produce ascomata in isolation. PCR analysis also showed that each of these isolates harboured either the MAT1-1 or the MAT1-2 idiomorph, but never both. Taken collectively, these results showed that the observed fertility in isolate CMW11056 was the result of the presence of two or more individuals of both mating types in a single culture.

The standard procedure for maintaining cultures of Ceratocystidaceae spp. is to transfer ascospore masses from the necks of ascomata of sporulating cultures to fresh plates. This is common mycological practise to ensure that ascomata and ascospore production is maintained after successive rounds of sub-culturing (HANLIN 1985). The practise is particularly important in mycological collections where dimensions of the ascomata and ascospores are essential for taxonomic descriptions of filamentous fungi. While this is not an ideal technique for culturing fungi for which the genomes are to be sequenced, in the case of the present study, it allowed for the elucidation of both MAT idiomorphs of $H$. omanensis, aiding in the identification of the two distinct mating types.

The results of this study show that $H$. moniliformis represents an example of selffertility conferred by unisexual reproduction. Previously, $H$. moniliformis has been treated as homothallic because single ascospore cultures were shown to produce ascomata and viable ascospores in culture (HARRINGTON 2007), an observation that was confirmed in the current study. Because ascospore production can be observed in a pure culture arising from a single ascospore, this reproductive strategy is a selfing event. Because we lack informative segregating markers, this form of reproduction would make it very difficult to trace recombination and the segregation of genes. 
Based on the gene content of the MAT locus in Ce. fimbriata (WILKEN et al. 2014), another homothallic fungus in the Ceratocystidaceae, our hypothesis was that $H$. moniliformis would harbour genes of both idiomorphs at its MAT locus. However, the bioinformatic analyses employed identified only the MAT1-2-1 gene and no genes associated with the MAT1-1 locus. Molecular analyses including dot blot analysis (data not shown), PCR amplification and sequencing were also unable to identify any MAT1-1 genes. These observations, combined with the ability of single ascospore cultures to produce ascomata with viable ascospores, suggest that the fungus represents an example of homothallism via unisexual reproduction. This would be the first time that a unisexual reproductive strategy has been found in a species of the Ceratocystidaceae, but it is known in other Sordariomycete species (GLASS and SMITH 1994).

The Sordariomycete species, $N$. africana, was the first fungal species in which unisexual reproduction was described (GLASS and SMITH 1994). To date, only the mat $A$ idiomorph (homologous to MAT1-1) has been identified in sexually reproducing isolates of $N$. africana. This fungus provides an excellent example of homothallic mating despite the absence of essential MAT genes (GLASS and SMITH 1994). It is thus possible that the genetic mechanisms of unisexual reproduction in $H$. moniliformis are analogous to those of $N$. africana.

A second species in which unisexual reproduction has been found is the basidiomycetous yeast, $C$. neoformans. This fungus has a well-described heterothallic mating system, where mating types have been classified as $\mathbf{\alpha}$ and $\mathbf{a}$ (reviewed in HEITMAN et al. 2013). Naturally occurring and clinical populations of $C$. neoformans show evidence of clonality and an extreme excess of the a mating type (KWON-Chung and BenNett 1978). While this was originally attributed to a predominance of asexual reproduction in the species, the discovery of a unisexual cycle also explained the observed clonality. This cycle involves a tissue differentiation process by cells of the a mating type that is similar to that in classical sexual reproduction (LIN et al. 2005). Though distantly related to species in the Ceratocystidaceae, the presence of a unisexual pathway in $C$. neoformans may provide insights into the genetic mechanisms employed by $H$. moniliformis to 
reproduce sexually in conditions where locating a suitable opposite mating partner may be highly improbable.

The MAT locus of $H$. omanensis is comparable to that of many heterothallic fungi. The presence of both MAT idiomorphs in the natural population of $\mathrm{H}$. omanensis, each harbouring either MAT1-1 or MAT1-2 genes is typical of most heterothallic species, including the model species $N$. crassa as well as Fusarium fujikuroi and Mycosphaerella graminicola (CONDE-FERRAEZ et al. 2007; GLASS et al. 1990a; StABEN and YANOFSKY 1990; YUN et al. 2000). However, it is not only the gene content of the locus that is conserved, the genes present just outside the $H$. omanensis MAT locus also feature as MAT locus-associated genes in many other ascomycetous fungi. SLA (AMSELEM et al. 2011; ARONSTEIN et al. 2007; WADA et al. 2012; WilkEN et al. 2014) and APC (CONDE-FerRAEZ et al. 2007; COZIJNSEN and HOWLETT 2003; WAALWIJK et al. 2002; WILKEN et al. 2014), in particular, have been described as MAT flanking genes in various species.

The fact that this locus seems so conserved across a number of heterothallic species raises the question as to whether $H$. moniliformis, also exhibiting the MAT12 locus structure seen in $\mathrm{H}$. omanensis, is able to undergo heterothallic reproduction in the presence of a partner possessing the MAT1-1 genes. In this study, only eight $H$. moniliformis isolates were available for screening and while these all harboured only the MAT1-2-1 gene, this does not exclude the possibility of finding the opposite mating type in the future. Furthermore, the similarity of the MAT1-2 idiomorphs of the two Huntiella species as well as the presence of the MAT1-1 idiomorph in $\mathrm{H}$. omanensis lends credence to the view that this idiomorph exists in $H$. moniliformis. However, it is important to consider that we were unable to perform successful interspecies crosses between MAT1 isolates of $H$. omanensis and MAT2 isolates of $H$. moniliformis and thus, in order to test this hypothesis, MAT1 isolates of $\mathrm{H}$. moniliformis need to be identified. Under the assumption that $H$. moniliformis is able to employ the same mating strategy as $H$. omanensis under favourable conditions, unisexual reproduction could represent an alternative reproductive strategy that isolates possessing the MAT1-2 idiomorph undergo in the absence of a possibly rare suitable partner. This would then represent a situation very similar to that seen in $C$. 
neoformans, rather than $N$. africana where the opposite mating type has never been found (GLASS and SMITH 1994).

The fact that $N$. africana possesses MAT1-1 sequence while $H$. moniliformis possesses only MAT1-2 sequence could indicate that the genetic mechanisms of unisexual reproduction do not rely on the unique function of the MAT genes. This might rather be due to differences in the downstream gene targets of the MAT transcription factors. This has been shown to be the case in $C$. neoformans, where a number of experiments have identified genes that are essential for heterothallic mating yet dispensable for unisexual reproduction. For example, the homeodomain Sxi1a/Sci2a complex is required for cell identity during heterothallic mating, but is not required for unisexual mating, where cell identity is not a prerequisite (FERETZAKI and HeitMAN 2013; Hull et al. 2002). In contrast, genes that play a large role in unisexual reproduction but contribute only modestly to heterothallic mating have also been identified. The Znf3 gene product is the dominant regulator of hyphal development in unisexual reproduction but is far less important for the same process in heterothallic mating (FERETZAKI and HEITMAN 2013). This supports the hypothesis that unisexual reproduction is not the result of a unique MAT locus function. However, it also suggests the presence of parallel pathways that can allow for sexual reproduction in species of only a single mating type (FERETZAKI and HEITMAN 2013). It may also explain why $\mathrm{H}$. omanensis is unable to reproduce unisexually, despite its highly similar MAT1-2 idiomorph.

Support for the view that unisexual reproduction is not the result of genes at a single MAT idiomorph replacing the functions of the other typically essential genes has been provided by transformation studies conducted in sterile Neurospora species. Transformation of a self-sterile relative with the $N$. africana mat $A$ sequence does not confer self-fertility seen in N. africana (GLASS and SMITH 1994). While transformation experiments have not been conducted using the MAT1-2 idiomorph of $H$. moniliformis, the presence of the highly similar MAT1-2-1 gene in $H$. omanensis provides a framework for comparison. The MAT1-2-1 protein shares a $91 \%$ similarity between the two Huntiella species, with the conserved DNA binding domain sharing a $97 \%$ similarity. However, this gene does not confer self-fertility in $\mathrm{H}$. omanensis. 
Unisexual reproduction, evidence for which has been found in $H$. moniliformis and various other fungi (AlBy and BENNETt 2011; GLASS and SMITH 1994; LIN et al. 2005), may have evolved as a mechanism allowing species to preserve sexual reproduction and its benefits while at the same time minimising the costs (ROACH et al. 2014). The cost of locating an opposite mating partner is a major barrier to efficient sexual reproduction in heterothallic fungi. This is particularly evident in natural populations of $C$. neoformans, where the a mating type makes up less than $1 \%$ of the population, making it incredibly costly for an a individual to locate a suitable, opposite mating partner (LIN et al. 2005). By permitting a individuals to mate with one another, this particular cost is minimized. Even though energy is required to locate a partner, all potential partners are compatible ( $\mathrm{NI}$ et al. 2013). At present, the $H$. moniliformis system appears to mirror that seen in N. africana (GLASS et al. 1990b), where only a single mating type is present in the natural population. It is possible that the unisexual mating system has evolved in a mating type-biased population, thereby preserving sexual reproduction despite the difficulty of locating an opposite mating partner. This would reduce the need for the rare mating type to be located and subsequently lead to a population composed entirely of a single mating type. In this situation, $C$. neoformans would represent an intermediate state of this process, with $N$. africana and possibly $H$. moniliformis representing the final state.

\section{CONCLUSION}

This study describes the first case of unisexual reproduction in the Ceratocystidaceae, a family known for its diverse sexual strategies. Unisexual reproduction was recognised relatively recently as a unique form of homothallism, allowing individuals to reproduce sexually, in the absence of a partner of opposite mating type. While this is apparently not a common sexual strategy in the fungi, it may have evolved in order to diminish the costs associated with typical sexual reproduction, while still maintaining its benefits. This study provides a foundation for further investigations into the evolution of sexual strategies across a variety of fungal species. It also provides a model organism in which the evolutionary benefits and molecular mechanisms of unisexual reproduction can be further studied. 


\section{ACKNOWLEDGEMENTS}

This project was financed by the University of Pretoria, the Department of Science and Technology (DST)/National Research Foundation (NRF) Centre of Excellence in Tree Health Biotechnology and the Genomics Research Institute (University of Pretoria Institutional Research Theme). This work is based on the research supported in part by a number of grants from the National Research Foundation of South Africa (including Grant specific unique reference number (UID) 83924). The Grant holders acknowledge that opinions, findings and conclusions or recommendations expressed in any publication generated by the NRF supported research are that of the author(s), and that the NRF accepts no liability whatsoever in this regard. We also thank Dr. Seonju Marincowitz for producing photgraphic images and descriptive plates of the two Huntiella species included in this study.

\section{REFERENCES}

Al-Subhi, A. M., A. O. Al-Adawi, M. Van WYK, M. L. Deadman and M. J. Wingfield, 2006 Ceratocystis omanensis, A New Species from Diseased Mango Trees in Oman. Mycological Research 110: 237-245.

Alby, K., and R. J. Bennett, 2011 Interspecies Pheromone Signaling Promotes Biofilm Formation and Same-Sex Mating in Candida albicans. Proceedings of the National Academy of Sciences 108: 2510-2515.

Altschul, S. F., W. Gish, W. Miller, E. W. Myers and D. J. Lipman, 1990 Basic Local Alignment Search Tool. Journal of Molecular Biology 215: 403-410.

Amselem, J., C. A. Cuomo, J. A. van Kan, M. Viaud, E. P. Benito et al., 2011 Genomic Analysis of the Necrotrophic Fungal Pathogens Sclerotinia sclerotiorum and Botrytis cinerea. PLoS Genetics 7: e1002230.

Aronstein, K., K. Murray, J. De Leon, X. Qin and G. Weinstock, 2007 High Mobility Group (HMG-box) Genes in the Honeybee Fungal Pathogen Ascosphaera apis. Mycologia 99: 553-561.

BARTON, N., 2009 Why Sex and Recombination?, pp. sqb. 2009.2074. 2030 in Cold Spring Harbor symposia on quantitative biology. Cold Spring Harbor Laboratory Press. 
Blanco-Ulate, B., P. Rolshausen and D. Cantu, 2013 Draft Genome Sequence of Neofusicoccum parvum Isolate UCR-NP2, a Fungal Vascular Pathogen associated with Grapevine Cankers. Genome announcements 1: e0033900313.

Bihon, W., M. J. Wingfield, B. Slippers, T. A. Duong and B. D. Wingfield, 2014 MAT Gene Idiomorphs suggest a Heterothallic Sexual Cycle in a Predominantly Asexual and Important Pine Pathogen. Fungal Genetics and Biology 62: 55-61.

Billiard, S., M. Lopez Villavicencio, M. Hood and T. Giraud, 2012 Sex, Outcrossing and Mating Types: Unsolved Questions in Fungi and Beyond. Journal of Evolutionary Biology 25: 1020-1038.

Conde-Ferraez, L., C. WaalwiJk, B. B. Canto-Canche, G. H. Kema, P. W. Crous et al., 2007 Isolation and Characterization of the Mating Type Locus of Mycosphaerella fijiensis, the Causal Agent of Black Leaf Streak Disease of Banana. Molecular Plant Pathology 8: 111-120.

Coppin, E., R. Debuchy, S. Arnaise and M. Picard, 1997 Mating Types and Sexual Development in Filamentous Ascomycetes. Microbiology and Molecular Biology Reviews 61: 411-428.

CoziJnsen, A. J., and B. J. Howlett, 2003 Characterisation of the Mating-Type Locus of the Plant Pathogenic Ascomycete Leptosphaeria maculans. Current Genetics 43: 351-357.

De Beer, Z., T. Duong, I. Barnes, B. Wingfield and M. Wingfield, 2014 Redefining Ceratocystis and allied genera. Studies in Mycology: http://dx.doi.org/10.1016/j.simyco.2014.1010.1001.

Debuchy, R., and E. Coppin, 1992 The Mating Types of Podospora anserina: Functional Analysis and Sequence of the Fertilization Domains. Molecular and General Genetics 233: 113-121.

Dyer, P. S., M. Paoletti and D. B. Archer, 2003 Genomics Reveals Sexual Secrets of Aspergillus. Microbiology 149: 2301-2303.

Feretzaki, M., and J. Heitman, 2013 Genetic Circuits that govern Bisexual and Unisexual Reproduction in Cryptococcus neoformans. PLoS Genetics 9: e1003688. 
Ferreira, A. V., S. SAUPE and N. L. GLASS, 1996 Transcriptional Analysis of the mtA Idiomorph of Neurospora crassa Identifies Two Genes in Addition to mtA-1. Molecular and General Genetics 250: 767-774.

Galagan, J. E., S. E. Calvo, K. A. Borkovich, E. U. Selker, N. D. Read et al., 2003 The Genome Sequence of the Filamentous Fungus Neurospora crassa. Nature 422: 859-868.

Gardiner, D. M., M. C. McDonald, L. Covareli, P. S. Solomon, A. G. Rusu et al., 2012 Comparative Pathogenomics reveals Horizontally Acquired Novel Virulence Genes in Fungi Infecting Cereal Hosts. PLOS pathogens 8: e1002952.

Glass, N. L., J. Grotelueschen and R. L. Metzenberg, 1990a Neurospora crassa A Mating-Type Region. Proceedings of the National Academy of Sciences 87: $4912-4916$.

Glass, N. L., R. L. Metzenberg and N. B. RAJU, 1990b Homothallic Sordariaceae from Nature: The Absence of Strains containing Only the a Mating Type Sequence. Experimental Mycology 14: 274-289.

GLASS, N. L., and M. L. SMITH, 1994 Structure and Function of a Mating-Type Gene from the Homothallic Species Neurospora africana. Molecular and General Genetics 244: 401-409.

Goodwin, S. B., S. B. M'Barek, B. Dhillon, A. H. Wittengerg, C. F. Crane et al., 2011 Finished Genome of the Fungal Wheat Pathogen Mycosphaerella graminicola Reveals Dispensome Structure, Chromosome Plasticity, and Stealth Pathogenesis. PLoS genetics 7: e1002070.

HABER, J. E., 1998 Mating-Type Gene Switching in Saccharomyces cerevisiae. Annual Review of Genetics 32: 561-599.

Hanlin, R. T., 1985 The Pedagogical Ascomycete. Mycologia 77: 1-10.

Harrington, T. C., 2007 The Genus Ceratocystis. Where does the Oak Wilt Fungus Fit, pp. in Proceedings of the 2nd National Oak Wilt Symposium.

HARRINGTON, T. C., and D. L. McNew, 1997 Self-fertility and Uni-Directional MatingType Switching in Ceratocystis coerulescens, a Filamentous Ascomycete. Current Genetics 32: 52-59.

Heitman, J., S. Sun and T. Y. JAmES, 2013 Evolution of Fungal Sexual Reproduction. Mycologia 105: 1-27. 
Hull, C. M., R. C. Davidson and J. Heitman, 2002 Cell Identity and Sexual Development in Cryptococcus neoformans are Controlled by the Mating-TypeSpecific Homeodomain Protein Sxi1 alpha. Genes \& Development 16: 30463060.

Hunter, S., P. Jones, A. Mitchell, R. Apweiler, T. K. Attwood et al., 2011 InterPro in 2011: New Developments in the Family and Domain Prediction Database. Nucleic Acids Research 40: D306-D312.

Kanamori, M., H. Kato, N. Yasuda, S. Kolzumi, T. L. Peever et al., 2007 Novel Mating Type-Dependent Transcripts at the Mating Type Locus in Magnaporthe oryzae. Gene 403: 6-17.

Kile, G., T. Harrington, Z. Yuan, M. Dudzinski and K. Old, 1996 Ceratocystis eucalypti sp. nov., A Vascular Stain Fungus from Eucalypts in Australia. Mycological Research 100: 571-579.

Kronstad, J. W., and C. Staben, 1997 Mating Type in Filamentous Fungi. Annual Review of Genetics 31: 245-276.

Kwon-Chung, K. J., and J. E. Bennett, 1978 Distribution of $\alpha$ and a Mating Types of Cryptococcus neoformans among Natural and Clinical Isolates. American Journal of Epidemiology 108: 337-340.

Lee, S. C., M. NI, W. LI, C. Shertz and J. Heitman, 2010 The Evolution of Sex: A Perspective from the Fungal Kingdom. Microbiology and Molecular Biology Reviews 74: 298-340.

LIN, X., and J. HEITMAN, 2007 Mechanisms of Homothallism in Fungi and Transitions between Heterothallism and Homothallism, pp. 35-57 in Sex in Fungi: Molecular Determination and Evolutionary Implications, edited by J. HEITMAN, J. W. Kronstad, J. W. TAylor and L. A. Casselton. ASM Press, Washington, D.C.

LIN, X., C. M. Hull and J. Heitman, 2005 Sexual Reproduction between Partners of the Same Mating Type in Cryptococcus neoformans. Nature 434: 1017-1021.

Machida, M., K. Asal, M. Sano, T. Tanaka, T. Kumagal et al., 2005 Genome Sequencing and Analysis of Aspergillus oryzae. Nature 438: 1157-1161.

Mandel, M. A., B. M. Barker, S. Kroken, S. D. Rounsley and M. J. Orbach, 2007 Genomic and Population Analyses of the Mating Type Loci in Coccidioides Species Reveal Evidence for Sexual Reproduction and Gene Acquisition. Eukaryotic Cell 6: 1189-1199. 
Marchler-Bauer, A., S. Lu, J. B. Anderson, F. Chitsaz, M. K. Derbyyshire et al., 2011 CDD: a Conserved Domain Database for the Functional Annotation of Proteins. Nucleic Acids Research 39: D225-D229.

Martin, S. H., B. D. Wingfield, M. J. Wingfield and E. T. Steenkamp, 2011 Structure and Evolution of the Fusarium Mating Type Locus: New Insights from the Gibberella fujikuroi Complex. Fungal Genetics and Biology 48: 731740 .

Mbenoun, M., Z. W. De Beer, M. J. Wingfield, B. D. Wingfield and J. Roux, 2014 Reconsidering Species Boundaries in the Ceratocystis paradoxa Complex, including a New Species from Oil Palm and Cacao in Cameroon. Mycologia 106: 757-784.

Merino, S. T., M. A. Nelson, D. J. Jacobson and D. O. Natvig, 1996 Pseudohomothallism and Evolution of the Mating-Type Chromosome in Neurospora tetrasperma. Genetics 143: 789-799.

Metzenberg, R. L., and N. L. Glass, 1990 Mating Type and Mating Strategies in Neurospora. Bioessays 12: 53-59.

Ni, M., M. Feretzaki, W. Li, A. Floyd-Averette, P. Mieczkowski et al., 2013 Unisexual and Heterosexual Meiotic Reproduction Generate Aneuploidy and Phenotypic Diversity de novo in the Yeast Cryptococcus neoformans. PLoS Biology 11: e1001653.

NieLSEN, R., 2006 Why Sex? Science 311: 960-961.

Oliver, S. G., Q. Van der Aart, M. Agostoni-Carbone, M. Aigle, L. Alberghina et al., 1992 The Complete DNA Sequence of Yeast Chromosome III. Nature 357: 38 - 46.

Pel, H. J., J. H. De Winde, D. B. Archer, P. S. Dyer, G. Hofmann et al., 2007 Genome Sequencing and Analysis of the Versatile Cell Factory Aspergillus niger CBS 513.88. Nature Biotechnology 25: 221-231.

Picard, M., R. Debuchy and E. Coppin, 1991 Cloning the Mating Types of the Heterothallic Fungus Podospora anserina: Developmental Features of Haploid Transformants Carrying Both Mating Types. Genetics 128: 539-547.

PŁazA, G., R. Upchurch, R. Brigmon, W. Whitman and K. UlFig, 2004 Rapid DNA Extraction for Screening Soil Filamentous Fungi using PCR Amplification. Polish Journal of Environmental Studies 13: 315-318. 
PögGeler, S., and U. KüCK, 2000 Comparative Analysis of the Mating-Type Loci from Neurospora crassa and Sordaria macrospora: Identification of Novel Transcribed ORFs. Molecular and General Genetics 263: 292-301.

Pöggeler, S., S. Risch, U. KüCK and H. D. OsiewaCz, 1997 Mating-Type Genes from the Homothallic Fungus Sordaria macrospora are Functionally Expressed in a Heterothallic Ascomycete. Genetics 147: 567-580.

Roach, K., M. Feretzaki, S. Sun and J. Heitman, 2014 Unisexual Reproduction, pp. 255-305 in Advances in Genetics, edited by T. Friedmann, J. DunLAP and F. GoodWIN. Elsevier Inc.

Sambrook, J., E. F. Fritsch and T. Maniatis, 1989 Molecular Cloning. Cold Spring Harbor Laboratory Press New York.

SeidL, V., C. Seibel, C. P. Kubicek and M. Schmoll, 2009 Sexual Development in the Industrial Workhorse Trichoderma reesei. Proceedings of the National Academy of Sciences 106: 13909-13914.

Sigrist, C. J., E. De Castro, L. Cerutti, B. A. Cuche, N. Hulo et al., 2012 New and Continuing Developments at PROSITE. Nucleic Acids Research: gks1067.

Staben, C., and C. YanOFsky, 1990 Neurospora crassa a Mating-Type Region. Proceedings of the National Academy of Sciences 87: 4917-4921.

Stanke, M., R. Steinkamp, S. WaAck and B. Morgenstern, 2004 AUGUSTUS: A Web Server for Gene Finding in Eukaryotes. Nucleic Acids Research 32: W309-W312.

Turgeon, B. G., and O. Yoder, 2000 Proposed Nomenclature for Mating Type Genes of Filamentous Ascomycetes. Fungal Genetics and Biology 31: 1-5.

Van der Nest, M. A., W. Bihon, L. De Vos, K. NAidoo, D. Roodt et al., 2014a Draft Genome Sequences of Diplodia sapinea, Ceratocystis manginecans, and Ceratocystis moniliformis. IMA Fungus 5: 135-140.

Van der Nest, M. A., P. M. Wilken, K. Naidoo, D. Roodt, J. A. Crouch et al., 2014b Draft Genome Sequences of Amanita jacksonii, Ceratocystis albifundus, Fusarium circinatum, Huntiella omanensis, Leptographium procerum, Rutstroemia sydowiana and Sclerotinia echinophila. IMA Fungus 5: 473-486.

Van WYK, M., J. Roux, I. Barnes, B. D. Wingfield and M. J. Wingfield, 2006 Molecular Phylogeny of the Ceratocystis moniliformis Complex and Description of $C$. tribiliformis sp. nov. Fungal Diversity 21: 181-201. 
WaalwiJk, C., O. Mendes, E. C. Verstappen, M. A. de Waard and G. H. Kema, 2002 Isolation and Characterization of the Mating-Type Idiomorphs from the Wheat Septoria Leaf Blotch Fungus Mycosphaerella graminicola. Fungal Genetics and Biology 35: 277-286.

Wada, R., J.-I. Maruyama, H. Yamaguchi, N. Yamamoto, Y. Wagu et al., 2012 Presence and Functionality of Mating Type Genes in the Supposedly Asexual Filamentous Fungus Aspergillus oryzae. Applied and Environmental Microbiology 78: 2819-2829.

Wilken, P. M., E. T. Steenkamp, M. J. Wingfield, Z. W. de Beer and B. D. WINGFIELD, 2014 DNA Loss at the Ceratocystis fimbriata Mating Locus Results in Self-Sterility. PloS One 9: e92180.

Wingfield, B., M. Van WYK, H. Roos and M. Wingfield, 2012 Ceratocystis: Emerging Evidence for Discrete Generic Boundaries, pp. 57-64 in Ophiostomatoid Fungi: Expanding Frontiers, edited by K. A. SEIFERT, Z. W. DE BEER and M. J. WINGFIELD. CBS-KNAW.

Witthuhn, R. C., T. C. Harrington, B. D. Wingfield, J. P. Steimel and M. J. WINGFIELD, 2000 Deletion of the MAT-2 Mating-Type Gene during UniDirectional Mating-Type Switching in Ceratocystis. Current Genetics 38: 4852.

XIAO, G., S.-H. Ying, P. Zheng, Z.-L. Wang, S. Zhang et al., 2012 Genomic Perspectives on the Evolution of Fungal Entomopathogenicity in Beauveria bassiana. Scientific reports 2.

Yu, J., T. E. Cleveland, W. C. Nierman and J. W. Bennett, 2005 Aspergillus flavus Genomics: Gateway to Human and Animal Health, Food Safety, and Crop Resistance to Diseases. Revista Iberoamericana de Micología 22: 194-202.

Yun, S.-H., T. Arie, I. Kaneko, O. Yoder and B. G. Turgeon, 2000 Molecular Organization of Mating Type Loci in Heterothallic, Homothallic, and Asexual Gibberella/Fusarium Species. Fungal Genetics and Biology 31: 7-20. 